\title{
Analysis on the Reform of the Professional Teaching System for Jade Caving
}

\author{
Guangzhao Yang \\ Hebei Academy of Fine Arts, Shijiazhuang Hebei, 050700, China
}

Keywords: Jade caving, Specialty, Teaching system, Reform.

\begin{abstract}
Jade is a apart of traditional culture in our country. With the development of the times, jade culture is gradually weakened, in order to make it inherit, carry forward the Chinese traditional jade carving in this technology age, many colleges and universities in our country carried out jade craving courses in the professional level; however, at present, Chinese jade in the professional teaching situation is not optimistic, many issues remains, is not conducive to jade craving culture This article conduct analysis on the professional education for jade craving, and to explore some effective method for jade craving in the reform of the teaching system, train more professional jade in the talents for our country, and push forward the Chinese jade culture.
\end{abstract}

\section{Analysis on the professional education system in jade craving}

Since the reformation and opening up,Chinese jade had gain rapid development in industrial, Nanyang jade hold its name both domestic and abroad. Meanwhile, it is also main driving force to promote economic development in Nanyang area. To make jade craving technique continually inherit, Nanyang Normal University, opened the professional jade craving course, is the first to set such a subject. With the development of society, there is some changes to the people's opinion , in the educational reformation, compare with other majors the jade craving made slow program. Although some changes been made by opening more courses, constantly increased enrollment of students and teaching mode innovation and combining theory and practice, it is still not enough. Th main issue for now is to cultivate more talents, by speed up the innovation and to meet the social needs of caving jade professionals.

Jade Caving is practical technology, with quite different with any other subjects; it is a very practical subject, requires students not only to master the theoretical knowledge, but also have the ability to complete task. To this target, during the caving jade professional courses, teachers should cultivate students hands-on and social practice abilities, as the focus of teaching.Each subject contain a amount of practical content and opened to the practice often and social life. in the actual teaching, part of the undergraduate colleges and universities in our country also continue to carry out jade in the professional, but the professional mainly as college enrollment, in the teaching, but it is even more difficult to achieve the combination of theory and practice teaching mode. lack of teaching experience. following problems that existed in the jade craving in the professional education level mainly exist in the .

First, despite the thousands of years of jade culture, however, our country the contemporary jade caving in the professional level is rather late. in the jade in the professional teaching, practice teaching not getting attention. Leading to the teaching reform of work can not be carried out smoothly. Coupled with China's jade in the professional teaching system is still not perfect, in the teaching practice, most remain in the classroom or experimental curriculum design. Even if the students have the opportunity to learn outside the school, many students have not mastered jade craving technologies, return to the classroom in a very limited time.. More serious is the jade in the professional practice of teaching content, serious and social disjointed, nowadays, jade in the professional teaching system should be provided with the professional practice of teaching contents, and also need to add internship, study, contests and other content, hand to mobilize students' enthusiasm, on the other hand and need to improve the practical ability of students. 
Secondly, in the professional teaching system of jade craving, should be the cultivation of students' ability of personality as the key task of teaching, teachers recognized that personality and innovation capability of students are the of training focus, therefore will be designated as one of the focus of teaching contents, in this process, ignoring the training the comprehensive ability of students' social culture [1]. Furthermore, in school students, often do not have the awareness of market competition, as been in the jade market is very fierce; training students awareness of market competition, need to cultivate the innovation ability of students at the same time, but also the professional characteristics, the cultivation of practice ability, and practical teaching, but ignore the awareness of market competition, training, causing Chinese jade craving in the professional training of students do not have professional quality, into the social work, difficult, not in a short period of time to. Furthermore, jade in the specialty in our country to carry out the practice teaching space is limited, school practice sites tend to meet the needs of teaching, even carry out school enterprise cooperation, but still can not for students to provide an ideal place to practice, established the implementation base only stay on the surface, students in this environment to practice learning, simply can not grasp the real jade in the knowledge. In addition, there is not enough high-quality teaching staff make it hard to improve the tutoring level effectively. In this very case, a new teaching system should take place of previos generation..

\section{Reformation for innovation for jade caving}

Jade caving teaching reformation will starting from the basic practice period

Practice is the focus of jade craving in the professional teaching; Jade caving teaching reformation will start from the basic practice period the first step is to carry on the reformation from starting from the basic practice period, according to the time division, second grade by learning the art appreciation, the corporate trainee to content; let students preliminary contact with the society, have a certain understanding of society to lay a foundation for future work. the three grade, can carry out market research and other training teaching content, students learn to investigate the market, analyze the market, to cultivate students' sense of market competition and the ability to solve practical problems. Fourth grade, mainly for graduation creation, the stage of learning, to study the practice of side ways to conducted, after four years studying, students have learned and summarized the jade in the knowledge , applied to practice, after overall researches. The target in this grad is to conducive and training students' ability in adapting to society ${ }^{[2]}$; The second step is to strengthen practice base construction work. currently jade craving and relative professionals are missing in practicing stage, which means the construction for practice base should strengthen. school can will converse some alumni relations companies into internal practicing base, students can undertake practical training in those enterprise. Or, schools can encourage students to submit their internship materials to social enterprises, to obtain social support, to carry out the construction of caving jade professional practicing base. In addition, the school will also employ the chairman of the company, as the school's practice teaching consultant, to offer opportunities for students of contacting with the community. About the professional the jade craving teaching team, the teachers should will , combined both classroom teaching content and social projects that enable the students to solve some existed social issues by their own knowledge. According to the actual situation, teachers will arrange for students involved in the jade caving related project, to a student group with more thank three students. These kind of project will only effective the classroom learning, but also to conduct real-word participate for everything they learned, both results are pretty ideal; Step three, managed students properly to realize the teaching systematization of jade craving. A proper managed students are essential to in the jade craving teaching practice, generally speaking there will such a phenomenon that many in line students play in teaching practice freely. To prevent from such occurrence and phenomenon, before the investigation work, teachers should allow students to identify their research topic, after the completion of the inspection work, submit a report on the investigation, to examine the report to master the research of students. In the summer, students participating in the enterprise practice, need 
strict management, to assure the students will be in accordance with the requirements by submitting practice reports; the practicing business will remains smooth communication with the school ,during the internship, and award the student with best fed backs from the enterprise.

\section{Practice teaching reform and innovation}

Innovation has always been the purpose of teaching in our country, the jade craving professional teaching is no exception, it should be aim in cultivating students' innovative thinking and innovation ability etc., Students in the learning process, and constantly explore, should dare to challenge and good mining new things. practice is the source of innovation. Therefore, in the jade craving education system reformation practice should be priority. Not only to improve students to have the spirit of perseverance to handle difficulties when conducts the research and the discussion,, but also cultivate the their innovative ability [4]. Due to the humanistic opinions when viewing professionalize of jade craving, the specialty is engaged during the education from all staffs, from need of life continues to experience and feel, and the formation of one of his own thinking and style, totally free compare to traditional forms. In teaching practice, teachers is to cultivate students innovative spirit, for example, in the teaching practice can carry out innovative education, like do variety of games to form the students' innovation ability;; adhere to the "to promote science, to develop and promote learning" teaching approach; teachers encourage students to challenge themselves, actively participate in various competitions schools to develop a comprehensive evaluation system of innovation; in order to mobilize students' enthusiasm, the creation of innovative scholarship, reward outstanding students in the innovation game. Secondly, competition adhere team form, consisting of teams from different grades and majors of jade craving. Each team to ten participating design scheme and his team at all levels as well as the design concept to express the, to the judges of the evaluation work, students in the game, from a new point of view of the continuous development, the analysis of the problem, is conducive to the cultivation of students' innovation consciousness. To adventurousness horizons, school will attend a number of determined authoritative professional competitions and exhibitions home and abroad, let students to set for their own learning goals, since the study, will take part in the match, and participating as an important content in the jade craving education, it will integrate the teaching, effectively cultivate students' initiative and enthusiasm , and the cultivation of students' innovative ability is significant.

\section{Enterprising practice}

Entrepreneurial practice teaching reform requires students to have the courage to find, dares to innovate, on top of that teachers will conduct lectures about business methods and skills , to generate comprehensive understanding to the society and to cultivate students' ability of market development. The concept of practice reform is from foreign teaching and entrepreneurial practice teaching reform, teaching reform practice of entrepreneurship, mainly uses for students in entrepreneurial activities. At present, college students entrepreneurial activity is very common, and have made certain effect, however, jade craving for professional college students entrepreneurial activity is very rare In order to carry out the jade craving in the professional college students entrepreneurial activities, content of the industry inclining jade jewelry art research, jade bonsai art in the research and jade pieces of art research. During the entrepreneurial process, conduct analysis from a professional point of view consequently. The characters for jade craving in the professional business are characteristics, with abundant resources, as spelldown, Nanyang region is rich in jade resources, has the traditional jade culture, and is the center of jade culture, which provide handy and local resources for the entrepreneurial process $\mathrm{m}$ [5]. Second, jade has great potential for revaluation. since the present market is not hard, people can buy a jade as an ornamental, or is used but in the professional field, different choices of will result to different the design style. Moreover the current market and economy situation provide a good platform for college entrepreneurs they can take the best advantage of the platform to conduct their own business. entrepreneurial process, students will be self employed work with their own hands and solve social problems by themselves like how to design their own jade sales out, obtains the customer approval, etc., it will give them a opportunity of contacting with the society, and to master the skills to communicate with customers. In entrepreneurial practice reform, teachers 
should encourage students to adhere to the entrepreneurial spirit, develop students awareness of market competition, dare to venture, innovation, integration with the society, to lay the foundation for future work, to prevent the entry of social work when ignorant, confused.

\section{Conclusion}

At present, jade craving education is not conducive to the inheritance of Chinese jade culture because for not enough attention as it should been pay for, only a few colleges and universities have fade craving major. Therefore,importance should be done to the existing jade craving education , in order to promote the development of jade culture; to reform the teaching system of jade craving and the establishment of jade craving the practice base; strengthen the building of the contingent of teachers team and encourage students to innovate, the courage to start, establish itself as a new generation of jade craving the professionals..

\section{References}

[1] Luo Feifei. Reflections on the construction of excellent courses in higher vocational colleges. Journal of Xinjiang Vocational University. 2011, (8).

[2] Wang Juanjuan, Jiang Yadong, Qi Wufu. Research on the reform of the curriculum reform of "jade carving technology" in Higher Vocational and technical education of Higher Vocational and technical college, Vocational Education Research, 2011,05:25-27.

[3] Wang Jia. Explore the art and design, Teaching system reform of jade Technology (Theory), 2011,02:191-192.

[4] Chang Ming. Jade in the skill talents the way Beijing Yiqing senior technical school of jade carving and design professional construction, The Chinese training, 2014,07:27-28.

[5] Ren Cai. Jade and caving painting teaching exploration and practice, Gemmological journal, 2014,01:88-92. 